\title{
The good, the bad and the ugly—or how to treat complications of complications
}

\author{
Martin Czerny, MD, MBA
}

\footnotetext{
From the University Heart Center Freiburg-Bad Krozingen, Bad Krozingen, Germany; and Faculty of Medicine, Albert Ludwigs University Freiburg, Freiberg, Germany.

Disclosures: Author has nothing to disclose with regard to commercial support.

Received for publication March 11, 2018; accepted for publication March 16, 2018; available ahead of print April $12,2018$.

Address for reprints: Martin Czerny, MD, MBA, Faculty of Medicine, Albert Ludwigs University Freiburg, University Heart Center Freiburg-Bad Krozingen, Südring 15, Bad Krozingen 79189, Germany (E-mail: martin. czerny@universitaets-herzzentrum.de).

J Thorac Cardiovasc Surg 2018;156:e107

$0022-5223 / \$ 36.00$

Copyright (C) 2018 by The American Association for Thoracic Surgery

https://doi.org/10.1016/j.jtcvs.2018.03.063
}

Extracorporeal life support (ECLS), otherwise known as venoarterial extracorporeal membrane oxygenation, is a lifesaver in various clinical scenarios, including as a bridge to transplant. This is the good thing.

Many patients in need of ECLS for any reason have long medical histories, and very often they have already undergone various cardiac or vascular procedures. A patient's history may present such challenges as obstacles in obtaining vascular access or the need to modify the ECLS circuit in response to potential game changers, such as previous left-sided mechanical valve replacement. This is the bad thing.

Irrespective of how meticulously you anticipate complications and how diligently you design your treatment plan, unexpected events always present an unpredictable gray zone when treating critically ill patients. This is the ugly thing. ${ }^{2}$

The report by Sandoval and colleagues ${ }^{1}$ in this issue of the Journal nicely shows how versatility, situational adaptiveness, and a disruptive surgical approach can keep you ahead even in the face of these challenges. Fortune frequently favors the bold, and this approach was followed by an early availability of a suitable organ, a desired situation that is owed to the excellent Spanish donor system.

Establishment of ECLS always mandates the prevention of further complications from those already existing. This is a particular challenge in the case of patients in need of ECLS after previous left-sided mechanical valve replacement. Creating a scenario of continuing flow, such as by success.

\section{References} Surg. 2018;156:e103-5.

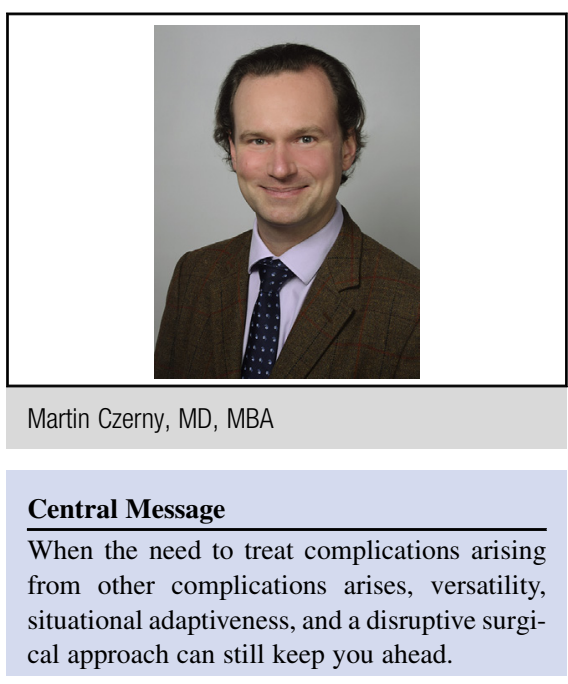

See Article page e103.

implanting an Impella (Abiomed, Inc, Danvers, Mass) pump, ${ }^{3}$ may serve as an additional means to prevent the kind of complication reported by Sandoval and colleagues. ${ }^{1}$ Still, all kinds of complications can arise from scenarios intended to prevent other complications. These are trade-offs in which versatility, situational adaptiveness, and-as in the report of Sandoval and colleagues ${ }^{1}$ - the courage to disruptive surgical solutions remain the most important factors in

1. Sandoval E, Ascaso M, Pereda D, Quintana E. Extracorporeal membrane oxygenation and mechanical valves: an unfriendly relationship. J Thorac Cardiovasc

2. Kreibich M, Czerny M, Benk C, Beyersdorf F, Rylski B, Trummer G. Thigh compartment syndrome during extracorporeal life support. J Vasc Surg Venous Lymphat Disord. 2017;5:859-63.

3. Cheng A, Swartz MF, Massey HT. Impella to unload the left ventricle during peripheral extracorporeal membrane oxygenation. ASAIO J. 2013;59:533-6. 